\title{
Stability of herbicides and their degradation products on graphitized carbon black extraction cartridges used for large volumes of surface water
}

\author{
H. Sabik ${ }^{1, *}$, R. Jeannot ${ }^{2}$ and E. Sauvard ${ }^{2}$ \\ ${ }^{1}$ St. Lawrence Centre, Environment Canada, 105 McGill Street, 7th Floor, Montreal, Quebec, Canada H2Y $2 E 7$ \\ ${ }^{2}$ BRGM, Service Minier National, Analyse, B.P. 6009, 45060 Orleans Cedex 02, France

\begin{abstract}
The stability of 18 herbicides (ten organonitrogens and eight phenylureas, including four degradation products), selected for the frequency of their detection in the environment, was evaluated under a variety of storage conditions. Large volumes of surface water $(4 \mathrm{~L})$ were extracted using large-particle-size graphitized carbon black cartridges (Carbopack B 60-80 mesh). The effects of temperature, matrix type, drying and solvent-washing of cartridges on the recovery of these contaminants, after different storage periods, were studied and compared to the conservation of surface water in bottles. After two months, there was no significant difference between the conserved surface water and the stored cartridges for the selected compounds. Cartridges kept at $-20{ }^{\circ} \mathrm{C}$ were better than those stored at $4{ }^{\circ} \mathrm{C}$ and $20^{\circ} \mathrm{C}$. The type of matrix water selected, in this case St. Lawrence surface water, appears to have a minor effect on the recovery of the target pesticides after cartridge storage. No improvement was observed in the recovery of any of the chemicals when the cartridges were dried or washed and stored in a solvent. After immediate surface-water extraction, the most ing or washing of the Carbopack B material.
\end{abstract} \\ practical storage condition for the target herbicides was found to be storage on cartridges in the dark at $-20^{\circ} \mathrm{C}$, with no solvent dry-
}

Keywords. Herbicides - degradation products - water analysis - stability - environmental analysis - solid-phase extraction Carbopack B.

\section{Introduction}

Determining the fluxes and fates of contaminants in the environment requires the analysis of a large number of samples. Field samples should be analysed immediately after collection to avoid any chemical, physical and biological analyte alterations. For a number of reasons, however, this is simply impossible. The loss of pesticides in water can be due to several processes, including hydrolysis, photolysis, biodegradation and oxidation. Indeed, the US Environmental Protection Agency (EPA) cited these processes for its decision to remove organophosphorus pesticides from the National Pesticide Survey (NPS) list [1,2]. By contrast, triazines, chloroacetanilides, phenoxyacids and some phenylureas seem to remain relatively stable $[2,3]$. It is essential to ensure the integrity of pesticide samples, from their collection to the data-reporting phase. A sample preservation study should therefore be performed as part of any analytical procedure.

Standard preservation techniques have been recommended by different government organizations for the storage of water samples in containers or after liquid-liquid extraction $[4,5]$. Studies on alternative pesticide stabilization techniques, including the use of freeze-drying, have been published [6]. The results obtained with this technique show that the stability of the compounds depends on their water solubility and vapour pressure. Other recent papers have demonstrated that solid-phase extraction (SPE) is a good alternative to the storage of pesticides preconcentrated from water samples [2,4,7-12]. In general, many pesticides are quite stable, except for compounds such as captan, carbofuran, fenamiphos, trifluraline, due to their physico-chemical properties and sample preconcentration conditions. Some examples of degradation processes include hydrolysis on Empore disks, hydrolysis and photochemical degradation on SPE cartridges, hydrolysis catalyzed by graphitized carbon black (GCB) surface, hydrolysis by residual water and biodegradation on GCB material [7-9]. Studies dealing with the stability of organic contaminants on filter or cartridgeextraction material (C-18, GCB, XAD-2) have already been published [2,4,7-12], although only three papers have focused on the use of GCB cartridges for stabilizing phenylureas and other selected pesticides $[7,12,13]$. None, however, deals with the storage of organonitrogen and phenylurea herbicides and their degradation products, after simultaneous extraction from large volumes of surface water using largeparticle-size GCB cartridges. The use of large volumes of surface water may increase the quantity of dissolved organic carbon (DOC) and microbial biomass retained by the cartridge material; conversely, the use of large-particle-size GCB cartridges may facilitate their passage, minimizing retention. In addition to $\mathrm{pH}, \mathrm{DOC}$, microbial biomass, and oxygen, the main factors affecting the stability of analytes in

*Correspondence and reprints.

Received July 27, 2000; revised October 31, 2000; accepted November 8, 2000. 
water samples are sample container-type and storage conditions (temperature, light, use of preservatives, and time interval between sampling and analysis).

Previous studies have reported the presence of herbicides and their degradation products in the St. Lawrence River (SLR) [13-18]. Atrazine, cyanazine, desethylatrazine, desisopropylatrazine, metolachlor and simazine were detected at concentrations ranging from 9 to $52 \mathrm{ng} / \mathrm{L}$ [18]. Because of the large-scale dilution of these contaminants in the river, concentrations of many chemicals are below the detection limits of standard analytical and sampling methods [19,20]. Consequently, the lowest detection limits possible are required to study the fate and the transport of contaminants in this river. Furthermore, in view of the increasingly stringent environmental measures being implemented, future regulations may well demand even lower detection limits. Two analytical methods were recently developed in the St. Lawrence Centre's laboratories to determine pesticides in large volumes of surface water (10 to $40 \mathrm{~L})$ at ppt levels $[15,16,18]$. A liquid-liquid extraction technique, using the Goulden large-sample extractor (GLSE), was developed first [15]. This technique had several disadvantages, including an inability to extract a large number of samples in a relatively short time. It was later replaced by a solid-phase extraction (SPE) technique using large-particle-size graphitized carbon black (GCB) cartridges (Carbopack B 60-80 mesh) [16,18]. This method was selected due to the ability of the large-particlesize GCB cartridges to extract target pesticides and their degradation products from large volumes of surface water (up to $20 \mathrm{~L}$ ) using a flow rate of $100 \mathrm{~mL} / \mathrm{min}$. This was not possible with either $\mathrm{C}_{18}$ or with polymeric cartridges. Furthermore, Tthe SPE technique is easily used for the onsite extraction of up to 24 samples at a time, making it ideal for extracting samples immediately after collection in order to avoid possible analyte alterations. The small volume of the cartridges allows for easy storage until elution/purification and analysis.

The aim of this study was to evaluate the stability, under a variety of storage conditions, of 18 herbicides (ten organonitrogens and eight phenylureas, including four degradation products), extracted from large volumes of surface water using large-particle-size GCB cartridges (Carbopack B 60-80 mesh). In addition to the advantage of the SPE technique for on-site extraction, positive results would mean reduced time and space requirements, since cartridges would be stored instead of surface water.

\section{Experiment}

\section{Reagents and chemicals}

All pesticides had purity greater than $95 \%$ (except for metolachlor, purity: $89 \%$ ) and were obtained from different suppliers. Ametryn, propazine and simazine were obtained from the US EPA. Atrazine, cyanazine, desethylatrazine (DEA), deisopropylatrazine (DIA), metribuzin, metolachlor, prometryn (used as surrogate) and terbutylazine (used as internal standard) were purchased from Riedel-de-Haën, distributed by Fisher Scientific (Montreal, Que., Canada). All phenylureas (chlortoluron, didesmethylisoproturon, diuron, isoproturon, linuron, methabenzthiazuron, monodesmethylisoproturon and monolinuron) were purchased from CIL Cluzeau Info Labo (Sainte-Foy-La Grande, France).

Ethyl acetate, acetonitrile and methanol (all distilled-inglass grade) were purchased from Caledon Laboratories Ltd. (Georgetown, Ont., Canada) and used without further cleanup. Reagent water was taken from a Milli-Q-UV Plus reagent-grade water system from Millipore (Bedford, Mass., USA).

A 293-mm Millipore stainless steel filter holder and a 293-mm-diameter Gelman fibre glass filter (TCLP type with $0.7 \mu \mathrm{m}$ nominal porosity) were used. The filters had been previously fired at $450{ }^{\circ} \mathrm{C}$ overnight and kept in a clean PTFE bag before use.

Twenty-litre stainless steel pressure containers (containing 17.85 L of liquid), purchased from Spartanburg Steel Products (Spartanburg, S.C., USA), were used to collect samples. Water was stored in 4-L umber glass bottles.

\section{Standard solutions}

Primary stock solutions of all pesticides were prepared individually at a concentration of $1 \mathrm{~g} / \mathrm{L}$ by weighing about $10 \mathrm{mg}$ of each substance in a $10-\mathrm{mL}$ volumetric flask and diluting to volume with methanol. Spiked solutions of the target pesticides were then prepared from these solutions in the same solvent at concentrations of $1 \mathrm{mg} / \mathrm{L}$ for triazines and their degradation products, and $2 \mathrm{mg} / \mathrm{L}$ for metolachlor and all phenylureas. A spiked solution of surrogate compound (prometryn) was prepared in methanol at a concentration of $10 \mathrm{mg} / \mathrm{L}$. Terbutylazine served as the internal standard (IS) and a working solution of $10 \mathrm{mg} / \mathrm{L}$ was prepared in methanol. Working solutions containing the target pesticides, surrogate and internal standard were prepared in methanol to construct the calibration curve. Concentrations of the targeted compounds and the surrogate ranged from $0.025-10 \mathrm{mg} / \mathrm{L}$, with the internal standard at a concentration of $1 \mathrm{mg} / \mathrm{L}$.

\section{Sampling and filtration}

Homogeneous surface-water samples $(17.85 \mathrm{~L})$ were collected at the Lévis station (opposite Quebec City) from the municipality's drinking water intake; a previous study has shown that water collected at this site is representative of the St. Lawrence water mass [21]. Surface water was sampled using a PTFE pneumatic pump, then filtered through 293-mm-diameter fibre glass filters and held in a 293-mmdiameter stainless steel filter holder [22]. Filtered water samples were collected in Spartanburg 20-L stainless steel containers. The characteristics [23] of selected surface waters are shown in table I. 


\section{Storage treatment}

Seven experiments were conducted using 4-L sample volumes of filtered surface water to determine the best storage conditions for the target herbicides. We evaluated and compared the effect of temperature, matrix $(\mathrm{pH}, \mathrm{DOC}$, microbial biomass), drying and solvent-washing of the cartridges on the recovery of the selected contaminants, after different storage periods, to their recovery in the bottled surface water. The effect of light exposure on these compounds was not studied. All the cartridges were covered with aluminum paper and stored, as were bottles of surface water, in the dark. The list of storage treatments is presented in table II.

\section{Solid-phase extraction}

Once at the laboratory, the filtered water was divided into 4L sample volumes. Each sample was spiked with $0.5 \mathrm{~mL}$ of spiked solution $(1 \mathrm{mg} / \mathrm{L}$ for triazines and their degradation products, and $2 \mathrm{mg} / \mathrm{L}$ for metolachlor and all phenylureas), then stirred for $5 \mathrm{~min}$ and set aside until extraction. All the samples used in the cartridge storage experiments were extracted immediately and the cartridges were stored in defined conditions (Tab. II). The surface waters used for sample conservation were stored in 4-L umber glass bottles at $4{ }^{\circ} \mathrm{C}$ in the dark until extraction. The selected solid-phase extraction technique has been well described by Sabik and Jeannot [18]. Briefly, a solid-phase extraction system (VAC ELUT SPS 24 SPE, purchased from Analytichem International) was used to aspirate each sample through a cartridge filled with $500 \mathrm{mg}$ of large-particle-size GCB material (Carbopack B 60-80 mesh) $(6.5 \times 1.4 \mathrm{~cm}$ internal diame- ter, polypropylene, purchased from Supelco, Oakville, Ont., Canada). These cartridges were first conditioned with $6 \mathrm{~mL}$ of ethyl acetate (later, substituted for dichloromethane and methanol), then with $20 \mathrm{~mL}$ of an acidic solution $(10 \mathrm{~g} / \mathrm{L}$ of ascorbic acid, adjusted to $\mathrm{pH} 2$ with concentrated $\mathrm{HCl}$ ). Following sample application, the cartridge was rinsed with $6 \mathrm{~mL}$ of Milli-Q water, then aspirated for $10 \mathrm{~min}$ to remove residual water. The target pesticides were completely eluted by running $50 \mathrm{~mL}$ of ethyl acetate through the cartridge. Lastly, the extract was concentrated to $2 \mathrm{~mL}$ by rotary evaporation, then reduced to near dryness under a nitrogen stream and transferred into $500 \mu \mathrm{L}$ of a mixture of methanol and water $(50: 50 \mathrm{v} / \mathrm{v})$ containing $0.5 \mu \mathrm{g}$ of the internal standard.

\section{Liquid chromatographic analysis}

This work was performed on a Varian liquid chromatography (LC) system coupled with a Finnigan SSQ 7000 mass spectrometer and equipped with an atmospheric pressure chemical ionization (APCI) interface. The details of the analytical technique have been well described by Sabik and Jeannot [18]. Briefly, LC separations were performed on a $25 \mathrm{~cm} \times 4.6 \mathrm{~mm}$ i.d. Kromasil column packed with $5-\mu \mathrm{m}$ particles coated with $\mathrm{C}_{18}$-bonded silica phase. Liquid chromatography was carried out using a Varian 9012 pump system, a Varian 9100 Autosampler and a Varian UV 9065 Polychrome diode-array detector. The flow rate of the mobile phase was $1 \mathrm{~mL} / \mathrm{min}$ with an injection volume of $20 \mu \mathrm{L}$. Linear gradient was 15-60\% acetonitrile in water for $50 \mathrm{~min}$, then held $15 \mathrm{~min}$. Atmospheric ion source parameters were set to a capillary temperature of $225^{\circ} \mathrm{C}$, APCI vaporizer

Table I. Characteristics of distilled water and surface water from the St. Lawrence River at the Lévis sampling station. Values are the minimum and the maximum observed during 1995 (mean of values)

\begin{tabular}{lcccccc}
\hline Sample origin & $\begin{array}{c}p H \\
\mathrm{n}=90\end{array}$ & $\begin{array}{c}\text { Conductivity }(\mu \mathrm{S} / \mathrm{cm}) \\
\mathrm{n}=90\end{array}$ & $\begin{array}{c}\text { DOC }(\mathrm{mg} / \mathrm{L}) \\
\mathrm{n}=90\end{array}$ & $\begin{array}{c}\text { POC }(\mathrm{mg} / \mathrm{L}) \\
\mathrm{n}=90\end{array}$ & $\begin{array}{c}\text { TOC (mg/L) } \\
\mathrm{n}=90\end{array}$ & $\begin{array}{c}\text { Faecal coliforms } \\
(\text { FCU/100 mL }) \\
\mathrm{n}=223\end{array}$ \\
\hline $\begin{array}{l}\text { Distilled water } \\
\text { Surface water }\end{array}$ & $\begin{array}{c}5.95 \\
6.8 .0(7.6)\end{array}$ & $162-279(234)$ & $2.15-6.05(3.7)$ & $0.13-1.66(0.51)$ & $2.5-6.87(4.22)$ & $10-2000(206)$ \\
\hline
\end{tabular}

Note: $\mathrm{DOC}=$ dissolved organic carbon; $\mathrm{POC}=$ particulate organic carbon; $\mathrm{TOC}=$ total organic carbon; $\mathrm{FCU}=$ faecal coliform units.

Table II. Storage treatments for target pesticides.

\begin{tabular}{lccccc}
\hline Experiment ID & $\begin{array}{c}\text { Number of } \\
\text { pesticides }\end{array}$ & Matrix & $\begin{array}{c}\text { Total storage } \\
\text { period (day) }\end{array}$ & $\begin{array}{c}\text { Number of } \\
\text { cartridges }\end{array}$ & Storage treatment \\
\hline Experiment A & 10 & Surface water & 60 & 5 & GCB cartridge stored dry, $-20^{\circ} \mathrm{C}$ \\
Experiment B & 10 & Surface water & 60 & 5 & GCB cartridge stored dry, $4^{\circ} \mathrm{C}$ \\
Experiment C & 10 & Surface water & 60 & 5 & GCB cartridge stored dry, $20^{\circ} \mathrm{C}$ \\
Experiment D & 10 & Surface water & 60 & 5 & GCB cartridge stored not dry, $4{ }^{\circ} \mathrm{C}$ \\
Experiment E & 10 & Surface water & 60 & 4 & Bottle stored, $4{ }^{\circ} \mathrm{C}$ \\
Experiment F & 10 & Milli-Q water & 60 & 5 & GCB cartridge stored dry, $4{ }^{\circ} \mathrm{C}$ \\
Experiment G & 8 & Surface water & 30 & 5 & GCB cartridge stored dry or solvent washed, $4{ }^{\circ} \mathrm{C}$ \\
\hline
\end{tabular}


temperature of $400{ }^{\circ} \mathrm{C}$ and Corona discharge intensity of $5 \mu \mathrm{A}$. Sheath gas was nitrogen at a pressure of $35 \mathrm{psi}$; auxiliary gas was also nitrogen, at a flow rate of $5 \mathrm{~mL} / \mathrm{min}$. Data acquisition was set to full scan mode. Scanned mass ranged from 50 to $450 \mathrm{u}$. Method detection limits (MDLs), retention times and selected ions for the target pesticides are presented in table III. MDLs were calculated, for each pesticide, by preparing a dilution of the final extracts $(500 \mu \mathrm{L})$ issued from 4-L filtered water samples (signal-to-noise ratio 10).

\section{Results and discussion}

Organonitrogen herbicides were selected for this study based on their intensity of use and on residual levels in the Great Lakes and the St. Lawrence River and its tributaries [1418,24-27]. Phenylureas are being used more and more, and there is a tendency to use them as a substitute for triazines, which have been a concern due to their worldwide presence in natural waters $[17,18,28-30]$. Large-particle-size GCB material (Carbopack B 60-80 mesh) has been chosen because it allows for the extraction of large volumes of surface water (up to $20 \mathrm{~L}$ ). This was not possible with either the small-particle-size material (Carbopack B 120-400 mesh) [16], or with $\mathrm{C}_{18}$ or polymeric cartridges. Terbutylazine was used as the internal standard because it was never detected in the SLR. It was later, substituted for atrazine- $\mathrm{d}_{5}[31]$.

With the exception of metribuzin, all selected herbicides exhibited percent recoveries (40-86 \%; Tab. IV and V) slightly lower than those obtained by Sabik and Jeannot (60-96 \%) [18]. This could be due to the fact that the extraction and analysis steps were carried out in different laboratories using different standard solutions. These values were obviously

Table III. Retention time (min), method detection limits (MDL) and selected ions for targeted pesticides.

\begin{tabular}{lccc}
\hline Pesticide & $\begin{array}{c}\text { Retention } \\
\text { time (min) }\end{array}$ & $\begin{array}{c}\text { MDL } \\
(\mathrm{ng} / \mathrm{L})\end{array}$ & $\begin{array}{c}\text { Selected } \\
\text { ion }\end{array}$ \\
\hline DIA & 9.2 & 0.9 & 174 \\
DEA & 14.3 & 0.8 & 188 \\
Simazine & 22.4 & 0.5 & 202 \\
Metribuzin & 23.1 & 0.6 & 215 \\
Cyanazine & 24.3 & 0.5 & 241 \\
Atrazine & 24.4 & 0.5 & 216 \\
Monodesmethylisoproturon & 29.3 & 0.5 & 193 \\
Methabenzthiazuron & 29.3 & 0.6 & $265+222$ \\
Chlortoluron & 31.4 & 0.8 & 213 \\
Isoproturon & 32.1 & 0.4 & 207 \\
Monolinuron & 32.2 & 1.6 & 215 \\
Didesmethylisoproturon & 32.5 & 0.5 & 179 \\
Ametryn & 35.4 & 0.4 & 228 \\
Diuron & 36.1 & 1.3 & 233 \\
Propazine & 36.2 & 0.4 & 230 \\
Prometryn & 41.2 & 0.3 & 242 \\
Linuron & 41.5 & 6.2 & 249 \\
Metolachlor & 43.5 & 0.9 & 284 \\
Pan & & & \\
\hline
\end{tabular}

lower than those obtained with the small-particle-size GCB material (Carbopack B 120-400 mesh), used for sample volumes of up to 1 L [13]. The "channeling" effect associated with the rapid flow of water samples through the cartridge can increase the equilibration time to the point whereby a fraction of the analytes, regardless of their nature, passes through the adsorbent bed unretained. A recent study conducted by Sabik [16] showed that the percent recovery of metribuzin improved when the ratio of water-sample volume to adsorbent material (Carbopack B 60-80 mesh) is decreased. With the exception of experiment $\mathrm{G}$, all cartridges were eluted with $50 \mathrm{~mL}$ of ethyl acetate. In fact, the phenylureas were better eluted with $50 \mathrm{~mL}$ of a mixture of dichloromethane and methanol (80:20, v/v) [13]. Given the large volumes of surface water involved in this study, it is difficult to consider samples in triplicate or to increase the number of sampling sites. Furthermore, previous studies have already shown that water collected at the sampling site selected for this study is representative of the St. Lawrence water mass [21], and that the extraction of large volumes of water by GCB cartridges (Carbopack B 60-80 mesh) has good reproducibility [16].

\section{Factors affecting pesticide losses during cartridge storage}

\section{Temperature}

Three experiments were conducted at different temperatures: $-20{ }^{\circ} \mathrm{C}$ (experiment A), $4{ }^{\circ} \mathrm{C}$ (experiment B) and $20{ }^{\circ} \mathrm{C}$ (experiment $\mathrm{C}$ ). All cartridges were stored in the dark after drying. Our results showed that temperature had a very slight effect on the storage of the target pesticides retained on the cartridge material. After two months, percent recoveries for the majority of selected herbicides decreased by between 2 and $11 \%$ (Tab. IV) when cartridges were stored at $4{ }^{\circ} \mathrm{C}$ or $20{ }^{\circ} \mathrm{C}$, instead of $-20{ }^{\circ} \mathrm{C}$. No significant new peak was observed on the chromatograms corresponding to different storage periods at $20^{\circ} \mathrm{C}$. Chromatograms corresponding to samples A00 (surface water, time $=0$ ) and A60 (cartridges stored dry at $-20{ }^{\circ} \mathrm{C}$ during 60 days) are presented in figures 1 and 2. Di Corcia and Marchetti [13] have shown that the stability of stored cartridges filled with a small-particle-size GCB material used in the extraction of small water samples $(250 \mathrm{~mL})$ is good, even at room temperature. The fact that concentrations were low in this study $(0.125-0.250 \mu \mathrm{g} / \mathrm{L})$ and the detection of new compounds unlikely, any explanation of these results is risky. Additional studies should be carried out to determine how temperature affects the loss of pesticides to the cartridges.

\section{Cartridge drying}

Two experiments were set up to evaluate the effect of cartridge drying on the storage of pesticides. Experiments B and D consisted of storing the dried and undried cartridges used for the extraction of 4-L sample volumes. Both cartridges were stored in the dark at $4{ }^{\circ} \mathrm{C}$. Our results showed no differences in the target pesticides, whether the cartridges were 


\section{Original articles}
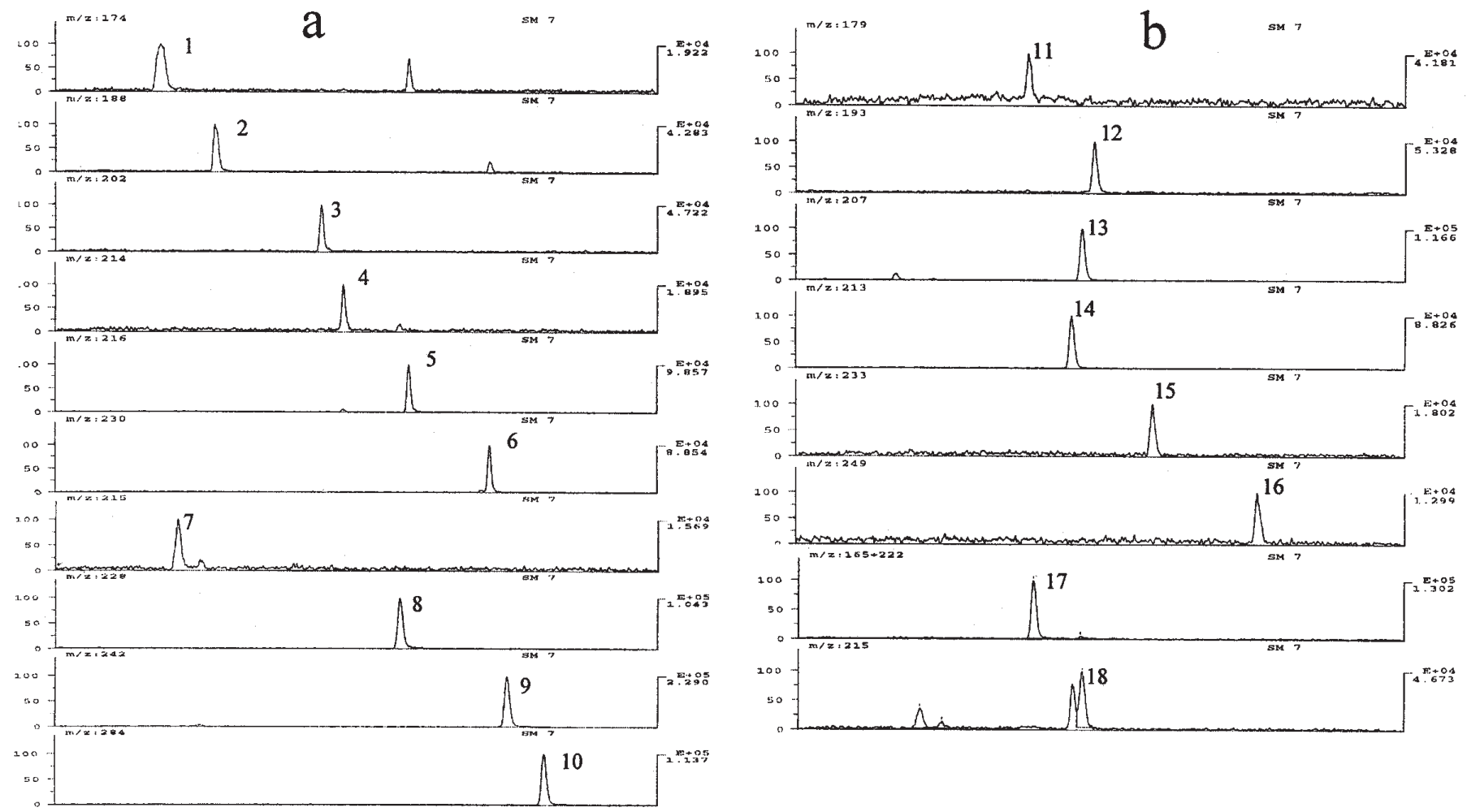

Figure 1. (a) Reconstructed ion chromatograms corresponding to sample A00 (surface water, time $=0$ ) from LC-APCI ${ }^{+}$-MS full scan analysis, spiked with the following compounds (around $0.125 \mu \mathrm{g} / \mathrm{L}$ for each compound, except for metolachlor: $0.250 \mu \mathrm{g} / \mathrm{L}): 1=\mathrm{DIA}(\mathrm{m} / z: 174)$ ); $2=$ DEA $(\mathrm{m} / \mathrm{z}: 188) ; 3=$ simazine $(\mathrm{m} / \mathrm{z}: 202) ; 4=$ cyanazine $(\mathrm{m} / \mathrm{z}: 214+241) ; 5=$ atrazine $(\mathrm{m} / \mathrm{z}: 216) ; 6=$ propazine $(\mathrm{m} / \mathrm{z}: 188+230) ;$ $7=$ metribuzin $(\mathrm{m} / \mathrm{z}: 215) ; 8=$ ametryn $(\mathrm{m} / \mathrm{z}: 228) ; 9=$ prometryn $(\mathrm{m} / \mathrm{z}: 242) ; 10=$ metolachlor $(\mathrm{m} / \mathrm{z}: 284)$.

(b) Reconstructed ion chromatograms corresponding to sample G0A (surface water, time $=0$ ) from LC-APCI ${ }^{+}$-MS full scan analysis, spiked with the following compounds (around $0.250 \mu \mathrm{g} / \mathrm{L}$ for each compound): $11=$ didesmethylisoproturon $(\mathrm{m} / \mathrm{z}: 179)$; $12=$ monodesmethylisoproturon $(\mathrm{m} / \mathrm{z}: 193) ; 13=$ isoproturon $(\mathrm{m} / \mathrm{z}: 207) ; 14=$ chlortoluron $(\mathrm{m} / \mathrm{z}: 213) ; 15=$ diuron $(\mathrm{m} / \mathrm{z}: 233) ; 16=1 \mathrm{inuron}(\mathrm{m} / \mathrm{z}: 249)$; $17=$ methabenzthiazuron $(\mathrm{m} / \mathrm{z}: 165+222) ; 18=$ monolinuron $(\mathrm{m} / \mathrm{z}: 215)$

dried or not (Tab. IV), leading us to think that, at $4{ }^{\circ} \mathrm{C}$, the chemicals did not hydrolyse on the cartridges.

\section{Aqueous matrix}

Two experiments were conducted to evaluate the effect of matrix water on the storage of pesticides. Experiments B and $\mathrm{F}$ consisted of storing cartridges used for the extraction of 4-L sample volumes of surface and Milli-Q waters, respectively. Both cartridges were stored in the dark at $4{ }^{\circ} \mathrm{C}$. The percent recoveries of all the target pesticides - except atrazine, which was sufficiently present in the surface water (0.040-0.050 $\mu \mathrm{g} / \mathrm{L})$ before spiking - were higher for Milli-Q water than for the surface water (Tab. IV) and decreased over time for the majority of selected chemicals when using surface water (Tab. IV). In fact, Sabik showed in a previous study [16] that the presence of colloids in surface water could affect percent recoveries. Taking this into account, one might expect that a fraction of the colloids and microbial biomass present in surface water could be retained by the cartridges, resulting in the chemical and biological transformation of the target pesticides. This was not the case for the Milli-Q water. Processes such as sorption, degradation, and transformation have all been reported to be affected by DOC [32]. No DOC or microbial biomass analysis was performed after the sample water had been passed through the cartridges. Further studies should be carried out to determine how the surfacewater matrix with different properties (high vs. low DOC) could affect the loss of pesticides to these cartridges.

\section{Solvent washing}

After surface-water extraction, the cartridges were washed with either $0.5 \mathrm{~mL}$ of methanol or $1 \mathrm{~mL}$ of ethyl acetate (experiment G). No improvement in recovery was observed when the cartridges were washed with these solvents as compared to dried cartridges (Tab. V). Percent recoveries for washed cartridges were even lower than for dried ones. This 


\section{Original articles}
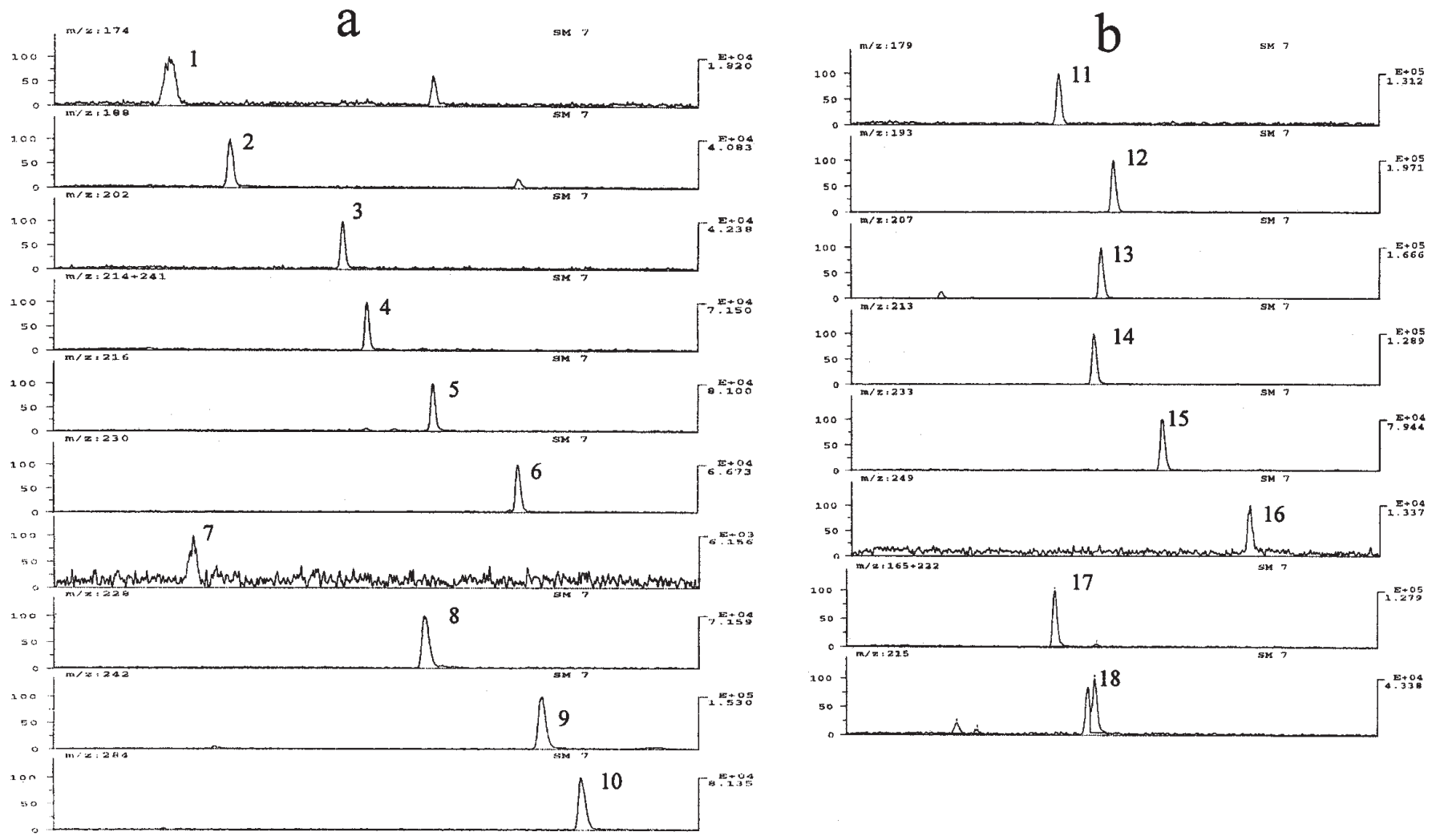

Figure 2. (a) Reconstructed ion chromatograms corresponding to sample A60 (surface water, stored dry at $-20{ }^{\circ} \mathrm{C}$ during 60 days) from LC$\mathrm{APCI}^{+}-\mathrm{MS}$ full scan analysis, spiked with the following compounds (around $0.125 \mu \mathrm{g} / \mathrm{L}$ for each compound, except for metolachlor: $0.250 \mu \mathrm{g} / \mathrm{L}): 1$ = DIA $(\mathrm{m} / \mathrm{z}: 174) ; 2=\operatorname{DEA}(\mathrm{m} / \mathrm{z}: 188) ; 3=$ simazine $(\mathrm{m} / \mathrm{z}: 202) ; 4$ = cyanazine $(\mathrm{m} / \mathrm{z}: 214+241) ; 5=$ atrazine $(\mathrm{m} / \mathrm{z}: 216) ;$ $6=$ propazine $(\mathrm{m} / \mathrm{z}: 188+230) ; 7=$ metribuzin $(\mathrm{m} / \mathrm{z}: 215) ; 8=$ ametryn $(\mathrm{m} / \mathrm{z}: 228) ; 9=$ prometryn $(\mathrm{m} / \mathrm{z}: 242) ; 10=$ metolachlor $(\mathrm{m} / \mathrm{z}: 284)$.

(b) Reconstructed ion chromatograms corresponding to sample G30A (surface water, stored dry at $4^{\circ} \mathrm{C}$ during 30 days) from LC-APCI+-MS full scan analysis, spiked with the following compounds (around $0.250 \mu \mathrm{g} / \mathrm{L}$ for each compound): $11=$ didesmethylisoproturon $(\mathrm{m} / z: 179)$; $12=$ monodesmethylisoproturon $(\mathrm{m} / \mathrm{z}: 193) ; 13=$ isoproturon $(\mathrm{m} / \mathrm{z}: 207) ; 14=$ chlortoluron $(\mathrm{m} / \mathrm{z}: 213) ; 15=$ diuron $(\mathrm{m} / \mathrm{z}: 233) ; 16=$ linuron $(\mathrm{m} / \mathrm{z}: 249) ; 17=$ methabenzthiazuron $(\mathrm{m} / \mathrm{z}: 165+222) ; 18=$ monolinuron $(\mathrm{m} / \mathrm{z}: 215)$

could be due to the elution of a fraction of the selected herbicides during washing, rather than to the degradation or transformation of these chemicals. Crescenzi et al. [7] opted for washing cartridges filled with small-particle-size GCB material (Carbopack B 120-400 mesh) with $0.5 \mathrm{~mL}$ of $\mathrm{MeOH}$, and then storing them in this same solvent. Our results show that for large-particle-size GCB material (Carbopack B 120-400 mesh) this is not necessary for the selected chemicals.

\section{Comparison between surface-water conservation and cartridge storage}

Two experiments were conducted to compare surface-water conservation with cartridge storage after surface-water extraction. Experiment B consisted of storing the cartridges used to extract 4-L sample volumes of surface water, whereas experiment E consisted of extracting the same volume of surface water after sample conservation in bottles. Both cartridges and surface water were stored in the dark at $4{ }^{\circ} \mathrm{C}$.
There was no observed difference in the target herbicides between surface-water conservation and cartridge storage (Tab. IV). Nevertheless, cartridges have the advantage of being easily maintained at much lower temperatures and their minimal time and storage space demands, in addition to their cost-effectiveness and on-site applicability.

\section{Conclusion}

This study has shown that it is possible to preserve herbicides and degradation products in large volumes of surface water, with no physical, chemical or biological alteration of these compounds, by using GCB cartridges (large-particle-size Carbopack B 60-80 mesh). Although no major difference was reported between surface-water conservation and cartridge storage for the selected herbicides, the latter had the advantage of being easily maintained at much lower temperatures, offering time and space savings with no need to transport 
Table IV. Results of percent recoveries (\%) for organonitrogen pesticides. Cartridges were stored in different conditions.

\begin{tabular}{|c|c|c|c|c|c|c|c|c|c|c|}
\hline $\begin{array}{l}\text { Sample } \\
\text { reference }\end{array}$ & $D I A$ & $D E A$ & Simazine & Cyanazine & Atrazine & Propazine & Metribuzin & Ametryn & Prometryn & Metolachlor \\
\hline $\mathrm{A} 00$ & 70 & 63 & 43 & 70 & 81 & 63 & 14 & 53 & 58 & 78 \\
\hline A01 & 72 & 61 & 42 & 71 & 82 & 66 & 2 & 54 & 58 & 79 \\
\hline A07 & 77 & 68 & 46 & 78 & 90 & 71 & 2 & 40 & 40 & 86 \\
\hline A 30 & $68(+1)$ & $66(+6)$ & $42(+2)$ & $70(+5)$ & $84(+9)$ & $64(+3)$ & $5(-4)$ & $43(+4)$ & $48(+6)$ & $79(+8)$ \\
\hline A60 & $70(+4)$ & $60(+1)$ & $41(0)$ & $70(+5)$ & $74(0)$ & $56(-4)$ & $4(-3)$ & $43(0)$ & $48(+1)$ & $64(0)$ \\
\hline B00 & 70 & 63 & 43 & 70 & 81 & 63 & 14 & 53 & 58 & 78 \\
\hline B01 & 72 & 59 & 40 & 63 & 78 & 60 & 1 & 51 & 60 & 76 \\
\hline B07 & 71 & 62 & 42 & 69 & 80 & 65 & 1 & 39 & 41 & 81 \\
\hline B30 & $64(-3)$ & $59(-1)$ & $37(-3)$ & $64(-1)$ & $75(0)$ & $59(-2)$ & $12(+3)$ & $39(0)$ & $38(-4)$ & $64(-7)$ \\
\hline B60 & $59(-7)$ & $55(-4)$ & $39(-2)$ & $67(-1)$ & $72(-2)$ & $58(-2)$ & $7(0)$ & $41(-2)$ & $43(-4)$ & $53(-11)$ \\
\hline $\mathrm{C} 00$ & 70 & 63 & 43 & 70 & 81 & 63 & 14 & 53 & 58 & 78 \\
\hline $\mathrm{C} 01$ & 68 & 60 & 41 & 68 & 78 & 64 & 3 & 51 & 57 & 77 \\
\hline $\mathrm{C} 07$ & 59 & 55 & 39 & 60 & 70 & 57 & 10 & 33 & 39 & 69 \\
\hline C30 & $67(0)$ & $58(-2)$ & $39(-1)$ & $63(-2)$ & $72(-3)$ & $54(-7)$ & $22(+13)$ & $35(-4)$ & $38(-4)$ & $60(-11)$ \\
\hline C60 & $65(-1)$ & $55(-4)$ & $36(-5)$ & $64(-4)$ & $71(-3)$ & $57(-3)$ & $16(+9)$ & $38(-5)$ & $43(-4)$ & $58(-6)$ \\
\hline D00 & 70 & 63 & 43 & 70 & 81 & 63 & 14 & 53 & 58 & 78 \\
\hline D01 & 64 & 57 & 38 & 65 & 77 & 63 & 2 & 49 & 57 & 76 \\
\hline D07 & 49 & 72 & 50 & 78 & 91 & 71 & 3 & 54 & 61 & 86 \\
\hline D30 & $64(-3)$ & $53(-7)$ & $40(0)$ & $63(-2)$ & $74(-1)$ & $60(-1)$ & $5(-4)$ & $34(-5)$ & $36(-6)$ & $70(-1)$ \\
\hline D60 & $56(-10)$ & $52(-7)$ & $32(-9)$ & $55(-13)$ & $62(-12)$ & $49(-11)$ & $11(+4)$ & $35(-8)$ & $38(-9)$ & $53(-11)$ \\
\hline E00 & 70 & 63 & 43 & 70 & 81 & 63 & 14 & 53 & 58 & 78 \\
\hline E01 & 62 & 53 & 34 & 57 & 68 & 54 & 5 & 39 & 44 & 67 \\
\hline E30 & $60(-7)$ & $55(-5)$ & $35(-5)$ & $57(-8)$ & $67(-8)$ & $54(-7)$ & $10(+1)$ & $39(0)$ & $42(0)$ & $63(-8)$ \\
\hline E60 & $77(+11)$ & $76(+17)$ & $48(+8)$ & $75(+8)$ & $87(+14)$ & $65(+5)$ & $5(-2)$ & $55(+12)$ & $61(+14)$ & $69(+5)$ \\
\hline F00 & 75 & 59 & 45 & 73 & 72 & 76 & 1 & 50 & 54 & 91 \\
\hline F01 & 72 & 58 & 43 & 73 & 72 & 70 & 0 & 38 & 44 & 83 \\
\hline F07 & 71 & 66 & 40 & 68 & 79 & 63 & 17 & 44 & 48 & 79 \\
\hline F30 & $79(+12)$ & $68(+8)$ & $46(+6)$ & $74(+9)$ & $76(+1)$ & $76(+15)$ & $0(-9)$ & $45(+6)$ & $49(+7)$ & $91(+20)$ \\
\hline F60 & $71(+5)$ & $58(-1)$ & $47(+7)$ & $74(+7)$ & $75(+2)$ & $76(+16)$ & $0(-7)$ & $46(+3)$ & $49(+2)$ & $88(+24)$ \\
\hline Mean 30 & 67 & 60 & 40 & 65 & 75 & 61 & 9 & 39 & 42 & 71 \\
\hline Mean 60 & 66 & 59 & 41 & 68 & 74 & 60 & 7 & 43 & 47 & 64 \\
\hline
\end{tabular}

Note: Numbers appearing alongside sample references A to F indicate time before cartridge elution, except for experiment $\mathrm{E}$ which refers to time before extraction (e.g. samples A00 to F00 were both extracted and cartridges eluted immediately; samples A01 to D01 and F01 were extracted immediately and cartridges eluted after one day of storage, etc.). Samples in experiment E01 to E60 were extracted after storage time indicated and eluted immediately after extraction. Mean 30/Mean 60: mean percent recovery for all experiments after 30 and 60 days. Values in parentheses are the difference between the experimental value and the mean calculated (e.g. A30 for atrazine: $(+9)=\mathrm{A} 30-$ Mean $30=84-75)$.

Table V. Percent recoveries (\%) of phenylureas. Cartridges were stored at $4{ }^{\circ} \mathrm{C}$ in the dark after drying or washing with an organic solvent.

\begin{tabular}{lcccccccc}
\hline $\begin{array}{l}\text { Sample } \\
\text { reference }\end{array}$ & Isoproturon & Chlortoluron & Diuron & Linuron & Monolinuron & $\begin{array}{c}\text { Methabenz- } \\
\text { thiazuron }\end{array}$ & $\begin{array}{c}\text { Didesmethyl- } \\
\text { isoproturon }\end{array}$ & $\begin{array}{c}\text { Monodesmethyl- } \\
\text { isoproturon }\end{array}$ \\
\hline G00 & 45 & 54 & 61 & 50 & 62 & 72 & 64 & 66 \\
G07 & 41 & 53 & 57 & 78 & 67 & 63 & 61 & 60 \\
G30A & $65(+7)$ & $72(+9)$ & $70(+8)$ & $59(+3)$ & $73(+13)$ & $74(+7)$ & $67(+9)$ & $71(+8)$ \\
G30B & $52(-6)$ & $56(-7)$ & $58(-4)$ & $47(-9)$ & $51(-9)$ & $61(-6)$ & $55(-3)$ & $57(-6)$ \\
G30C & $57(-1)$ & $60(-3)$ & $59(-3)$ & $63(7)$ & $56(-4)$ & $65(-2)$ & $52(-6)$ & $60(-3)$ \\
Mean G30 & 58 & 63 & 62 & 56 & 60 & 67 & 58 & 63 \\
\hline
\end{tabular}

Note: Numbers appearing alongside sample references G indicate time before cartridge elution (e.g. samples G00 was extracted and cartridge eluted immediately; sample G07 was extracted immediately and cartridges eluted after seven days of storage). Mean G30: mean percent recovery for all experiments after 30 days. Values in parentheses are the difference between the experimental value and the mean calculated (e.g. G30A for isoproturon: $(+7)=\mathrm{G} 30 \mathrm{~A}-\mathrm{Mean}$ G30 $=$ 65-58). G30A: cartridge dried, G30B : cartridge washed with $1 \mathrm{~mL}$ of ethyl acetate, G30C: cartridge washed with $0.5 \mathrm{~mL}$ of methanol. 


\section{Original articles}

sample containers. SPE using GCB cartridges could be used for on-site extraction, with the analysis being performed in a laboratory a few days or even weeks later. The use of large volumes of surface water may increase the quantity of DOC and microbial biomass retained by the cartridge material, whereas the use of large-particle-size GCB cartridges may facilitate the passage of these variables and minimize their retention by the cartridge material. The results have shown that only temperature and matrix water $(\mathrm{pH}, \mathrm{DOC}$, microbial biomass), in this case St. Lawrence surface water, can affect the storage of the target herbicides on GCB cartridges. No hydrolysis was observed for samples free of these parameters (Milli-Q water) or when cartridges were stored at $-20{ }^{\circ} \mathrm{C}$ or $4{ }^{\circ} \mathrm{C}$. No improvement in recovery was obtained when cartridges were dried or washed with an organic solvent. Following immediate surface-water extraction, the most practical storage condition for the target herbicides was determined to be the storage of cartridges in the dark at $-20{ }^{\circ} \mathrm{C}$, with no drying or washing of the Carbopack B material with solvent.

\section{References}

1. Barcelo, D.; Chiron, S.; Lacorte, S.; Martinez, E.; Salau, J. S.; Hennion, M. C. Trends Anal. Chem. 1994, 13, 352-365.

2. Munch, D. J.; Frebis, C. P. Environ. Sci. Technol. 1992, 26, 921-925.

3. Barcelo, D.; Hennion, M.-C. Trace Determination of Pesticides and their Degradation Products in Water: Techniques and Instrumentation in Analytical Chemistry; Elsevier, 1997, pp 116-129.

4. Jeannot, R. Int. J. Environ. Anal. Chem. 1994, 57, 231-236.

5. Jones, T. L. Organophosphorus Pesticide Standards: Stability Study; EPA 600/X-92/040, Office of Research and Development, US EPA, Las Vegas, NE, 1992.

6. Martin-Esteban, A.; Fernandez, P.; Camara, C.; Kramer, G. N.; Maier, E. A. Int. J. Environ. Anal. Chem. 1997, 67, 125-141.

7. Crescenzi, C.; Di Corcia, A.; Madbouly, M. D.; Samperi, R. Environ. Sci. Technol. 1995, 29, 2185-2196.

8. Green, D. R.; Le Pape, D. Anal. Chem. 1987, 59, 699-703.

9. Sensman, S. A.; Lavy, T. L.; Mattice, J. D.; Meyers, B. M.; Skulman, B. W. Environ. Sci. Technol. 1993, 27, 516-519.

10. Lacorte, S.; Ehresmann, N.; Barcelo, D. Environ. Sci. Technol. 1995, 29, 2834-2841.

11. Ferrer, I.; Barcelo, D. J. Chromatogr. A 1997, 778, 161-170.

12. Sabik, H.; Jeannot, R. J. Chromatogr. A 2000, 879, 73-82.

13. Di Corcia, A.; Marchetti, D. J. Chromatogr. A 1991, 541, 365373.

14. Rondeau, B. Pesticides dans les tributaires du fleuve SaintLaurent 1989-1991; Environment Canada, Quebec Region, St. Lawrence Centre, Scientific and Technical Repor ST-62, 1996.

15. Sabik, H.; Fouquet, A.; Proulx, S. Analusis 1997, 25, 267-273.
16. Sabik, H. Int. J. Environ. Anal. Chem. 1998, 72, 113-128.

17. Pham, T. T.; Rondeau, B.; Sabik, H.; Proulx, S.; Cossa, D. Can. J. Fish. Aquat. Sci. 2000, 57, 78-85.

18. Sabik, H.; Jeannot, R. J. Chromatogr. A 1998, 818, 197-207.

19. APHA-AWWA-WEF. Standard Methods for the Examination of Water and Wastewater, 17th ed. (Greenberg, A.E., Clesceri, L.S., Eaton, D.A., eds.) Washington, D.C. 1992.

20. U.S. Environmental Protection Agency, Test Methods for Evaluating Solid Waste, SW-846; Office of Solid Waste, GPO: Washington, D.C. 1986.

21. Rondeau, B. Validation d'une station de référence pour le suivi de la qualité des eaux dans le fleuve Saint-Laurent à Québec; Environment Canada, St. Lawrence Centre. Scientific and Technical Report, ST-175, 1999.

22. Cossa, D.; Rondeau, B.; Pham, T. T.; Proulx, S.; Quémerais, B. Principes et pratiques d'échantillonnage d'eaux naturelles en vue du dosage de substances et d'éléments présents à l'état de traces et ultra-traces; Environment Canada, Quebec, Region, Environmental Conservation, St. Lawrence Centre, Working Document DT-5, 1996.

23. Cossa, D.; Pham, T. T.; Rondeau, B.; Quémerais, B.; Proulx, S.; Surette, C. Bilan massique des contaminants chimiques dans le fleuve Saint-Laurent; Environment Canada, Quebec, Region, Environmental Conservation, St. Lawrence Centre, Working Document ST-163, 1998.

24. Gorse, I. Bilan des ventes de pesticides au Québec en 1995, Ministère de l'Environnement et Faune du Québec, Québec, 1997.

25. Conseil Canadien des Ministres des Ressources et de l'Environnement-CCMRE Recommandations pour la qualité des eaux au Canada; Groupe de Travail sur les recommandations pour la qualité des eaux du Conseil Canadien des Ministres des Ressources et de l'Environnement (CCMRE), Division des Objectifs de Qualité des Eaux, Direction Générale des Eaux Intérieures, Environnement Canada, 1987.

26. Stevens, R. J. J.; Neilsen, M. A. J. Great Lakes Res. 1989, 15, 377-393.

27. Neilson, M. A.; Stevens, R. J..J.; Biberhofer, J.; Goulden, P. D.; Anthony, D. H. J. A Large-Sample Extractor for Determining Organic Contaminants in the Great Lakes; WQB/OR Technical Bulletin 157, Environment Canada, Burlington, Ontario, 1988.

28. Thurman, E. M.; Goolsby, D. A.; Meyer, M. T.; Kolpin, D. W. Environ. Sci. Technol. 1991, 25, 1794-1796.

29. Squillace, P. J.; Thurman, E. M. Environ. Sci. Technol. 1992, 26, 538-545.

30. Schottler, S. P.; Eisenreich, S. J. Environ. Sci. Technol. 1994, 28, 2228-2232.

31. Jeannot, R.; Sabik, H.; Amalric, L.; Sauvard, E.; Proulx, S.; Rondeau, B. Chromatographia 2001 (Submitted).

32. Sensei, N.; Chen, Y. in Toxic Organic Chemicals in Porous Media, Ecological Studies 73, Z. Gerstl, Y. Chen, U. Mingelgrin \& B. Yaron (Eds), Springer-Verlag, Berlin, 1989, pp. 37-90. 